\title{
Delta(9)-tetrahydrocannabivarin impairs epithelial calcium transport through inhibition of TRPV5 and TRPV6
}

Citation for published version (APA):

Janssens, A., Silvestri, C., Martella, A., Vanoevelen, J. M., Di Marzo, V., \& Voets, T. (2018). Delta(9)tetrahydrocannabivarin impairs epithelial calcium transport through inhibition of TRPV5 and TRPV6. Pharmacological Research, 136, 83-89. https://doi.org/10.1016/j.phrs.2018.08.021

Document status and date:

Published: 01/10/2018

DOI:

10.1016/j.phrs.2018.08.021

Document Version:

Publisher's PDF, also known as Version of record

Document license:

Taverne

Please check the document version of this publication:

- A submitted manuscript is the version of the article upon submission and before peer-review. There can be important differences between the submitted version and the official published version of record.

People interested in the research are advised to contact the author for the final version of the publication, or visit the DOI to the publisher's website.

- The final author version and the galley proof are versions of the publication after peer review.

- The final published version features the final layout of the paper including the volume, issue and page numbers.

Link to publication

\footnotetext{
General rights rights.

- You may freely distribute the URL identifying the publication in the public portal. please follow below link for the End User Agreement:

www.umlib.nl/taverne-license

Take down policy

If you believe that this document breaches copyright please contact us at:

repository@maastrichtuniversity.nl

providing details and we will investigate your claim.
}

Copyright and moral rights for the publications made accessible in the public portal are retained by the authors and/or other copyright owners and it is a condition of accessing publications that users recognise and abide by the legal requirements associated with these

- Users may download and print one copy of any publication from the public portal for the purpose of private study or research.

- You may not further distribute the material or use it for any profit-making activity or commercial gain

If the publication is distributed under the terms of Article $25 \mathrm{fa}$ of the Dutch Copyright Act, indicated by the "Taverne" license above, 


\title{
$\Delta^{9}$-tetrahydrocannabivarin impairs epithelial calcium transport through inhibition of TRPV5 and TRPV6
}

\author{
Annelies Janssens $^{\mathrm{a}, \mathrm{b}}$, Cristoforo Silvestri ${ }^{\mathrm{c}, 1}$, Andrea Martella ${ }^{\mathrm{c}, 2}$, Jo M. Vanoevelen ${ }^{\mathrm{d}}$, \\ Vincenzo Di Marzo ${ }^{\mathrm{c}, \mathrm{e}}$, Thomas Voets ${ }^{\mathrm{a}, \mathrm{b}, *}$ \\ ${ }^{a}$ Laboratory of Ion Channel Research, VIB Center for Brain \& Disease Research, Leuven, Belgium \\ ${ }^{\mathrm{b}}$ Department of Cellular and Molecular Medicine, KU Leuven, Leuven, Belgium \\ c Endocannabinoid Research Group, Institute of Biomolecular Chemistry, C.N.R., Pozzuoli, Italy \\ d Department of Genetics \& Cell Biology, Section Clinical Genetics \& GROW, School for Oncology and Developmental Biology, Maastricht University Medical Centre, \\ Maastricht, The Netherlands \\ e Canada Excellence Research Chair on the Microbiome-Endocannabinoidome Axis, Université Laval, Québec, Canada
}

\section{A R T I C L E I N F O}

\section{Keywords:}

Phytocannabinoids

$\Delta^{9}$-tetrahydrocannabivarin

Epithelial calcium transport

TRPV5

TRPV6

Ossification

\begin{abstract}
A B S T R A C T
Compounds extracted from the cannabis plant, including the psychoactive $\Delta^{9}$-tetrahydrocannabinol (THC) and related phytocannabinoids, evoke multiple diverse biological actions as ligands of the $\mathrm{G}$ protein-coupled cannabinoid receptors CB1 and CB2. In addition, there is increasing evidence that phytocannabinoids also have nonCB targets, including several ion channels of the transient receptor potential superfamily. We investigated the effects of six non-THC phytocannabinoids on the epithelial calcium channels TRPV5 and TRPV6, and found that one of them, $\Delta^{9}$-tetrahydrocannabivarin (THCV), exerted a strong and concentration-dependent inhibitory effect on mammalian TRPV5 and TRPV6 and on the single zebrafish orthologue drTRPV5/6. Moreover, THCV attenuated the drTRPV5/6-dependent ossification in zebrafish embryos in vivo. Oppositely, 11-hydroxy-THCV (THCV-OH), a product of THCV metabolism in mammals, stimulated drTRPV5/6-mediated $\mathrm{Ca}^{2+}$ uptake and ossification. These results identify the epithelial calcium channels TRPV5 and TRPV6 as novel targets of phytocannabinoids, and suggest that THCV-containing products may modulate TRPV5- and TRPV6-dependent epithelial calcium transport.
\end{abstract}

\section{Introduction}

Extracts from the plant Cannabis sativa contain a large number of different compounds derived from a diterpene structure, generally known as phytocannabinoids [1]. The best characterised phytocannabinoid is $\Delta^{9}$-tetrahydrocannabinol (THC), which is the main mediator of the psychoactive effects of marijuana, by acting as an agonist of the $\mathrm{G}$ protein-coupled cannabinoid receptor $\mathrm{CB} 1$ in the brain [2]. In addition to $\mathrm{CB} 1$ and the closely related CB2 [3], there is extensive evidence for other pharmacological targets of THC and related phytocannabinoids $[4,5]$. In particular, several members of the transient receptor potential (TRP) superfamily of cation channels have been identified as non-CB1/ non-CB2 molecular targets of phytocannabinoids [6-9]. These include the thermosensory channels TRPM8 and TRPA1 as well as four heat- activated members of the vanilloid subfamily, TRPV1, TRPV2, TRPV3 and TRPV4 $[7,8,10,11]$. Based on these findings and on the discovery that endocannabinoids such as anandamide or 2-arachidonoyl glycerol can activate TRPV1 and TRPV4 [12,13], TRP channels have been put forward as a class of ionotropic cannabinoid receptors that may potentially contribute to the diverse physiological effects of endo- and phytocannabinoids in the brain, gut, peripheral sensory system and skin $[5,14,15]$.

In addition to the heat-activated TRPV1-TRPV4, the vanilloid subfamily contains two additional members, TRPV5 and TRPV6, which are functionally distinct in that they lack significant temperature sensitivity and exhibit an exquisite selectivity for calcium compared to monovalent cation channels $[6,16-18]$. The latter property lies at the basis of their physiological function as gate-keepers in calcium (re)absorbing

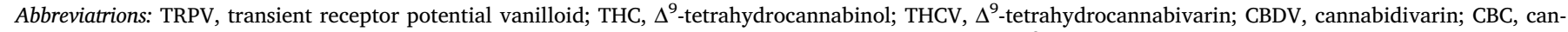
nabichromene; CBD, cannabidiol; CBG, cannabigerol; CBGV, cannabigerovarin; THCV - OH, 11-hydroxy- $\Delta^{9}$-tetrahydrocannabivarin

* Corresponding author at: Laboratory of Ion Channel Research, VIB Center for Brain \& Disease Research, Leuven, Belgium.

E-mail address: thomas.voets@kuleuven.vib.be (T. Voets).

${ }^{1}$ Present address: Centre de Recherche de l'Institut Universitaire de Cardiologie et Pneumologie de Québec, Université Laval, Québec, Canada.

${ }^{2}$ Present address: Molecular Physiology Group, LIC, Faculty of Science, Leiden, The Netherlands. 
epithelia in kidney and gut [19]. Whether these calcium-selective TRPVs are modulated by phytocannabinoids has remained unknown. Here, we show that mammalian TRPV5 and TRPV6, as well as the single TRPV5/6 orthologue in zebrafish are potently inhibited by $\Delta^{9}$-tetrahydrocannabivarin (THCV). Moreover, we found that treatment of zebrafish larvae with THCV partially reproduces the bone formation deficit of the zebrafish trpv5/6 loss-of-function mutant matt-und-schlapp [18]. Taken together, our results suggest that low micromolar concentrations of THCV can affect calcium homeostasis through inhibition of calcium-selective epithelial TRP channels.

\section{Methods}

\subsection{Cells and cellular assays}

HEK293 at passage numbers $15-30$ were grown in DMEM containing $10 \%(\mathrm{v} / \mathrm{v})$ fetal calf serum, $4 \mathrm{mM}$ L-alanyl-L-glutamine, $100 \mathrm{U}$ $\mathrm{ml}^{-1}$ penicillin and $100 \mu \mathrm{g} \mathrm{ml} l^{-1}$ streptomycin at $37^{\circ} \mathrm{C}$ in a humidity controlled incubator with $10 \% \mathrm{CO}_{2}$. Cells were transiently transfected with rabbit TRPV5, mouse TRPV6 or zebrafish TRPV5/6 constructs cloned in the bicistronic pCINeo/IRES/GFP vector using TransIT-293 transfection reagent. Experiments were performed between 16 and $24 \mathrm{~h}$ after transfection

Currents were recorded in the whole-cell configuration of the patchclamp technique using an EPC-9 amplifier and Patchmaster software (HEKA Elektronik, Lambrecht/Pfalz, Germany). Positively transfected cells were identified based on GFP fluorescence. Data were sampled at $5-20 \mathrm{kHz}$ and digitally filtered off-line at $1-5 \mathrm{kHz}$. Currents were measured during 200-ms voltage-ramps from -150 to $+100 \mathrm{mV}$ applied at a rate of $0.5 \mathrm{~Hz}$. Patch electrodes had resistances between 2 and $4 \mathrm{M} \Omega$ when filled with the intracellular solution, which contained (in mM): $150 \mathrm{NaCl}, 5$ EGTA, $5 \mathrm{MgCl} 2,10$ Hepes, pH 7.2 with NaOH. Series resistances were between 3 and $10 \mathrm{M} \Omega$ and were compensated for 60-80 \%, reducing voltage errors to less than $10 \mathrm{mV}$. The extracellular solution contained (in $\mathrm{mM}$ ): $150 \mathrm{NaCl}, 1 \mathrm{CaCl}_{2}, 1 \mathrm{MgCl}_{2}, 10 \mathrm{Hepes,} \mathrm{pH}$ 7.4 with $\mathrm{NaOH}$. When indicated, $\mathrm{CaCl}_{2}$ was omitted from this solution, to obtain a nominally calcium-free solution.

For intracellular $\mathrm{Ca}^{2+}$ measurments, transfected cells were incubated with $2 \mu \mathrm{M}$ fura- 2 acetoxymethyl ester for $30 \mathrm{~min}$ at $37^{\circ} \mathrm{C}$. Fluorescence was measured during alternating illumination at 340 and $380 \mathrm{~nm}$ using a Cell ${ }^{\mathrm{M}}$ (Olympus, Aartselaar, Belgium) fluorescence microscopy system, and absolute calcium concentration was calculated from the ratio of the background-corrected fluorescence signals at these two wavelengths $\left(\mathrm{R}=\mathrm{F}_{340} / \mathrm{F}_{380}\right)$ as $\left[\mathrm{Ca}^{2+}\right]=\mathrm{K}_{\mathrm{m}} \times\left(\mathrm{R}-\mathrm{R}_{\min }\right) /\left(\mathrm{R}_{\max }-\mathrm{R}\right)$, where $K_{m}, R_{\min }$ and $R_{\max }$ were estimated from in vitro calibration experiments with known calcium concentrations. The extracellular solution in these experiments contained (in $\mathrm{mM}$ ): $150 \mathrm{NaCl}, 6 \mathrm{KCl}, 1 \mathrm{MgCl}_{2}$, 10 Hepes, pH 7.4 with $\mathrm{NaOH}$, supplemented with between 0 and $3.3 \mathrm{mM} \mathrm{CaCl}_{2}$, as indicated.

\subsection{Zebrafish ossification assay}

Zebrafish (Danio rerio) embryos and larvae were obtained from a stable laboratory strain and raised at $28.5^{\circ} \mathrm{C}$ on a $14 \mathrm{~L}: 10 \mathrm{D}$ photoperiod according to the Zebrafish Book [20]. Embryos were raised in E3 embryo medium ( $5 \mathrm{mM} \mathrm{Na} \mathrm{Cl}, 0.17 \mathrm{mM} \mathrm{KCl}, 0.33 \mathrm{mM} \mathrm{CaCl}_{2}, 0.33 \mathrm{mM}$ $\mathrm{MgSO}_{4}, 0.00001 \%$ Methylene Blue) until staged at 3 days post fertilization (dpf) following distinctive morphological markers [21], after which healthy larvae were placed in 24-well plates at a density of up to 10 larvae/ml/well and exposed to drug solutions. All the drugs were dissolved in ethanol and diluted with E3 media to the indicated concentrations maintaining a final vehicle concentration of $0.1 \%$. During the exposure period the drugs were replaced daily and the larvae kept at $28.5^{\circ} \mathrm{C}$ on a standard photoperiod. The number of ossified vertebral centers in 8dpf larvae was quantified by staining with alizarin red [22]. Control and treated larvae were placed on glass slide embedded in a $3 \%$ $(\mathrm{w} / \mathrm{v})$ methylcellulose solution and then photographs were taken on a Leica DMI 6000B microscope.

\subsection{Data and statistical analysis}

Statistical analyses were performed using OriginPro 9 (OriginLab Corporation, Northampton, US). Group data are presented as mean \pm SEM, or as individual data points (Fig. 3D). Group sizes are provided as $\mathrm{n}$, representing the number of experimentally independent values. Normality of all datasets was evaluated using the KolmogorovSmirnov test, and when this test indicated that normality could not be rejected, statistical significance was determined using Student's twotailed t-test, one-way or two-way ANOVA, as indicated. P $<0.05$ was deemed to constitute the threshold for statistical significance. Tukey's post hoc test was used to compare groups when ANOVA yielded a main effect with $\mathrm{P}<0.05$.

\subsection{Materials}

Cannabinoids extracted and purified from Cannabis sativa, namely: THCV ( $\Delta^{9}$-tetrahydrocannabivarin), CBDV (cannabidivarin), CBC (cannabichromene), CBD (cannabidiol), CBG (cannabigerol), CBGV (cannabigerovarin) and THCV-OH (11-hydroxy- $\Delta^{9}$-tetrahydrocannabivarin; produced via a synthetic route from the parent compound THCV) were provided by GW Pharma Ltd., Salisbury, UK. The cannabinoids were of $>95 \%$ purity. The chemicals used for preparing solutions for the cellular assays were supplied by Sigma-Aldrich (Overijse, Belgium), fura-2 acetoxymethyl ester by Gentaur Molecular Products (Brussels, Belgium), TransIT-293 transfection reagent by Mirus Bio (Madison, US), and cell culture reagents by Life Technologies (Merelbeke, Belgium).

\section{Results}

We used the whole-cell patch-clamp technique to evaluate the effect six non-THC cannabinoids, namely THCV, CBDV, CBC, CBD, CBG and CBGV, on mammalian TRPV5 and TRPV6 heterologously expressed in HEK293 cells. Under physiological ionic conditions, TRPV5 and TRPV6 are highly calcium-selective channels, but in the absence of calcium they mediate large monovalent currents [17,23,24]. The activity of both channels is tightly regulated by calcium-dependent negative feedback mechanism, whereby a rise in intracellular calcium inhibits channel activity. In view of these properties, were performed patchclamp experiments using calcium-free intra- and extracellular solutions, resulting in stable, inwardly rectifying currents mediated by $\mathrm{Na}^{+}$ions. After maximal development of the TRPV5- and TRPV6-mediated currents during cell dialysis with the EGTA-containing intracellular solution, the different cannabinoids were applied at a concentration of $10 \mu \mathrm{M}$, and their effect on the current amplitude at $-80 \mathrm{mV}$ was assessed after $3 \mathrm{~min}$ or steady-state inhibition. As shown in Fig. 1A,B, $10 \mu \mathrm{M}$ THCV had a reversible inhibitory effect of on both TRPV5 and TRPV6. The inhibitory effect of THCV was concentration-dependent (Fig. 1C), with $\mathrm{IC}_{50}$ values of $4.8 \pm 0.6 \mu \mathrm{M}$ and $9.4 \pm 1.4 \mu \mathrm{M}$ for TRPV5 and TRPV6, respectively. The effects of all other tested cannabinoids at a concentration of $10 \mu \mathrm{M}$ did not reach statistical significance (Fig. 1D).

Zebrafish (Danio rerio) express one single orthologue of TRPV5/ TRPV6, and loss-of-function mutations in the trpv5/6-gene result in severe deficits in bone formation in the matt-und-schlapp mutant [18]. Therefore, zebrafish represent an instrumental in vivo model to evaluate the effect of modulating epithelial calcium channels on calcium homeostasis. As a first step, we performed whole-cell patch-clamp recordings in HEK293 cells expressing drTRPV5/6 to evaluate the effect of THCV. Notably, in comparison with its mammalian orthologues, drTRPV5/6-mediated currents in HEK293 are relatively stable in $\mathrm{Ca}^{2+}$. containing extracellular solution, thus allowing us to test the inhibitory 

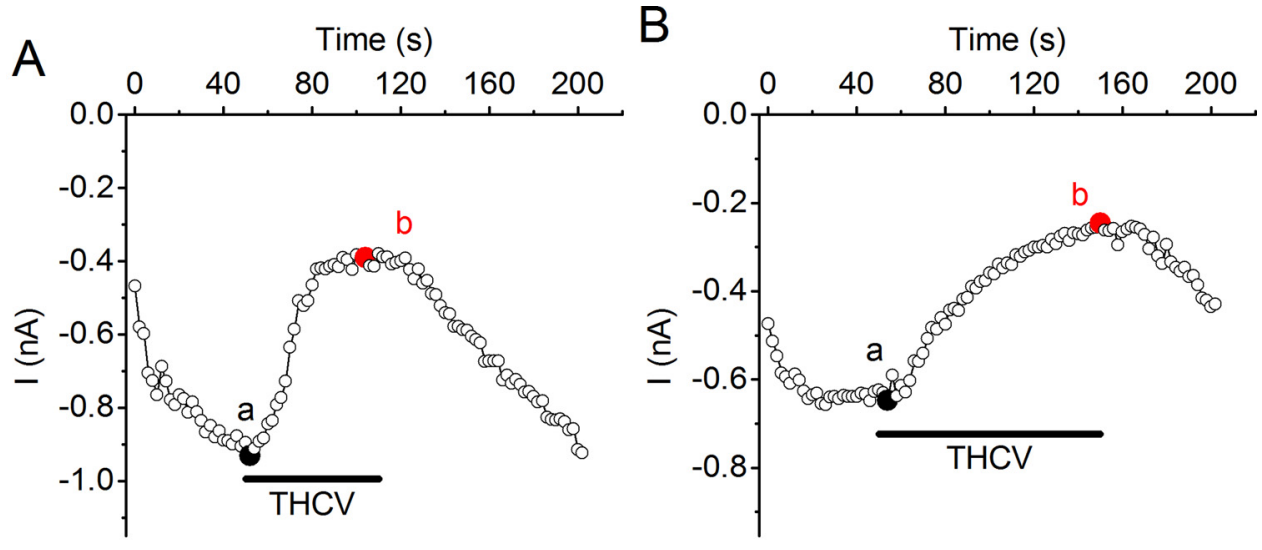

Fig. 1. Inhibition of monovalent TRPV5 and TRPV6 currents by THCV. (A) Representative time course (top) of inward currents at $-80 \mathrm{mV}$ in a HEK293 cell expressing rabbit TRPV5 following establishment of the wholecell configuration (time 0 ) and upon application of $10 \mu \mathrm{M}$ THCV, and current-voltage relations (bottom) at the indicated time points. (B) Same as (A), but in a cell expressing mouse TRPV6. (C) Concentration-response curve for the inhibition of TRPV5 and TRPV6 by THCV ( $n=5$ for each data point). (D) Summary of the inhibitory effect of different phytocannabinoids (all at $10 \mu \mathrm{M}$ ) on TRPV5 and TRPV6 ( $n=5$ for each channel/cannabinoid combination). Horizontal full and dashed lines indicate mean \pm SEM of vehicle control $(\mathrm{n}=5){ }^{* *}, \mathrm{P}<0.01$ versus vehicle control; one-Way ANOVA with Tukey's post hoc test.
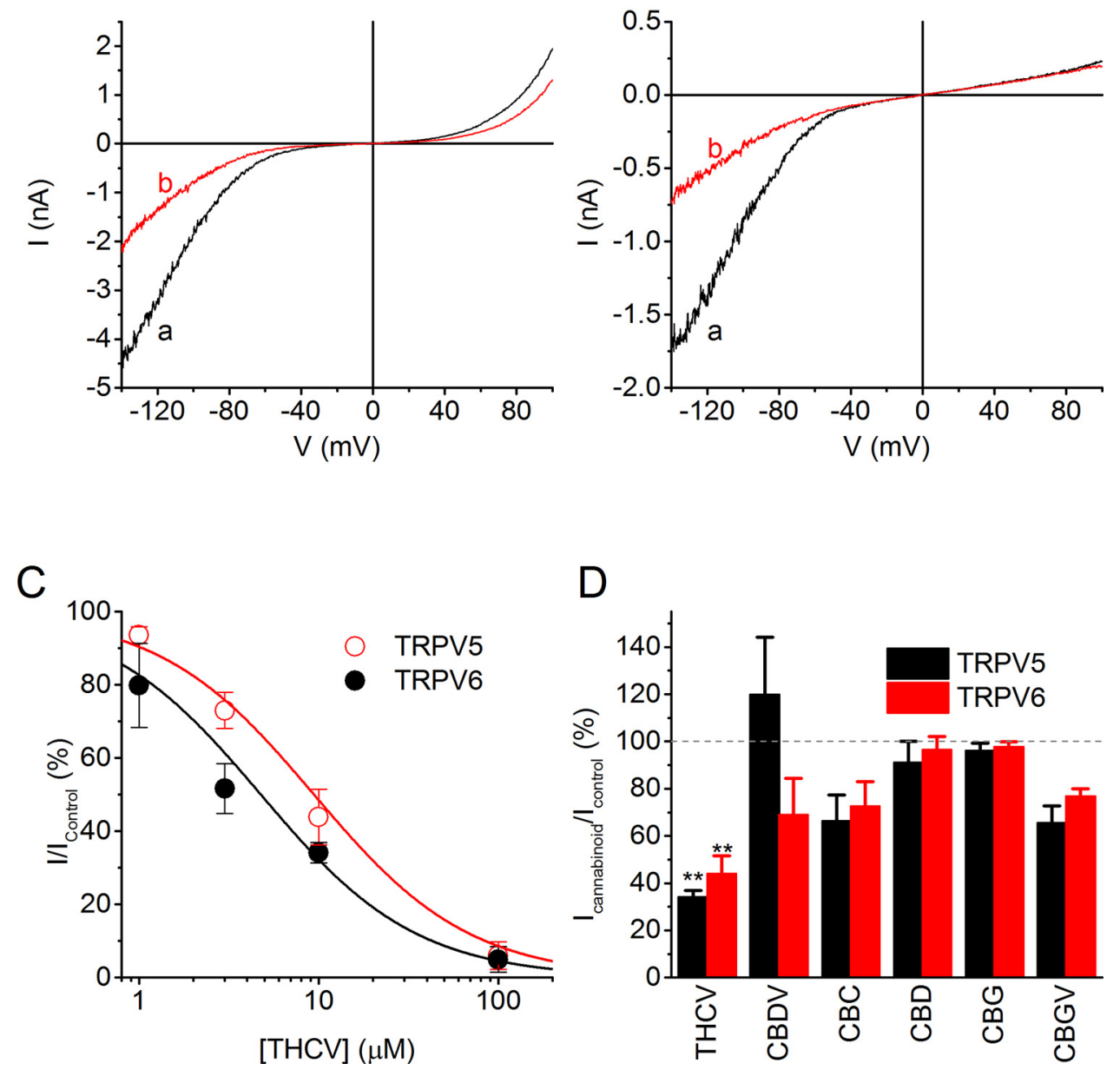

effect of THCV in more physiological ionic conditions. In the presence of $1 \mathrm{mM} \mathrm{Ca}^{2+}$, application of THCV at 1 and $10 \mu \mathrm{M}$ induced a reversible inhibition of inward drTRPV5/6-mediated currents (Fig. 2A,C).

Like THC, the main metabolic pathway for THCV occurs via cytochrome P450-dependent oxidation, leading to the formation of 11-hydroxy tetrahydrocannabivarin $(\mathrm{THCV}-\mathrm{OH})[25,26]$. We tested the effect of THCV $-\mathrm{OH}$ at a concentration of $10 \mu \mathrm{M}$, and observed that, in contrast to THCV, it has a small but significant potentiating effect on drTRPV5/6-mediated currents (Fig. 2B,C).

Using Fura-2-based intracellular calcium imaging, we confirmed that THCV has a strong inhibitory effect on drTRPV5/6-mediated calcium uptake in HEK293 cells [18], whereas THCV - OH has a mild potentiating effect (Fig. 3A). Finally, we tested the effect of THCV and
THCV - OH on the development of the axial skeleton in zebrafish embryos. Embryos were treated with THCV (1 or $3 \mu \mathrm{M})$ or THCV - OH (3 $\mu \mathrm{M}$ ) from day 3 post fertilization ( $3 \mathrm{dpf}$ ), and ossification was assessed using alizarin red staining at $8 \mathrm{dpf}$ (Fig. 3B) and quantified as the number of ossified vertebral centers [22]. In comparison to controls, embryos treated with THCV showed a significant reduction in the number of ossified vertebral centers, whereas THCV - $\mathrm{OH}$ resulted in an increased number of ossified vertebral centers (Fig. 3B).

\section{Discussion}

Our present results reveal that THCV acts as an antagonist, with low micromolar potency, of mammalian TRPV5 and TRPV6 as well as of 

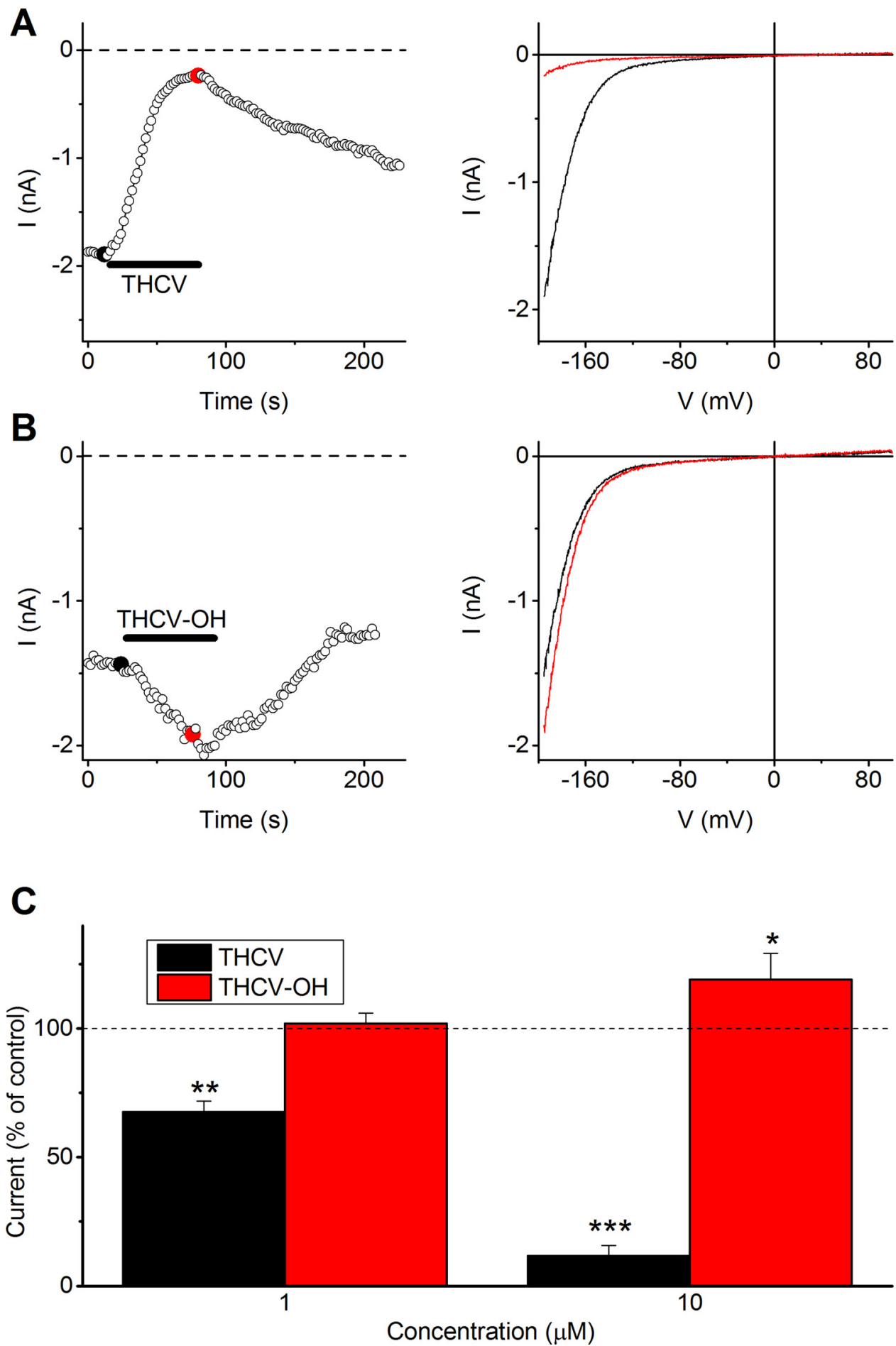

Fig. 2. Modulation of drTRPV5/6-mediated currents in $\mathrm{Ca}^{2+}$-containing extracellular solution by THCV and THCV-OH. (A) Representative time course (left) of inward currents at $-80 \mathrm{mV}$ in a HEK293 cell expressing drTRPV5/6 following establishment of the whole-cell configuration (time 0) and upon application of $10 \mu \mathrm{M} \mathrm{THCV}$, and current-voltage relations (right) at the indicated time points. (B) Same as (A), but upon application of $10 \mu \mathrm{M} \mathrm{THCV}-\mathrm{OH}$. (C) Summary of the effect of THCV and THCV $-\mathrm{OH}$ at $-80 \mathrm{mV}$ ( $\mathrm{n}=5$ for each condition). ${ }^{*}, * *$ and ${ }^{* * *}$ : $\mathrm{P}<0.05, \mathrm{P}<0.01$ and $\mathrm{P}<0.001$ versus vehicle control; unpaired two-tailed $\mathrm{t}$-test.

zebrafish drTRPV5/6. Other tested cannabinoids (CBDV, CBC, CBD, CBG and $\mathrm{CBGV}$ ) were ineffective at the tested dose of $10 \mu \mathrm{M}$. The specific antagonistic effect of THCV on mammalian TRPV5 and TRPV6 contrasts with the agonistic effect of THCV and several other cannabinoids on the four other mammalian members of the vanilloid subfamily of TRP channels, TRPV1-TRPV4 $[7,8]$. However, inhibitory effects on the more distantly related cold- and menthol-activated channel TRPM8 have been reported for several cannabinoids, including THCV inhibiting the channel with an $\mathrm{IC}_{50}$ value of $\sim 0.9 \mu \mathrm{M}$ [8].

Within the mammalian TRP channels, the epithelial calcium channels TRPV5 and TRPV6 stand out as the two most calcium-selective members, being almost exclusively permeable for calcium under physiological ionic conditions. They are both mainly expressed in the apical membrane of calcium-transporting epithelia, where they are postulated to act as gatekeepers for transcellular calcium transport [19]. In addition, TRPV6 expression is upregulated in prostate cancer and various 

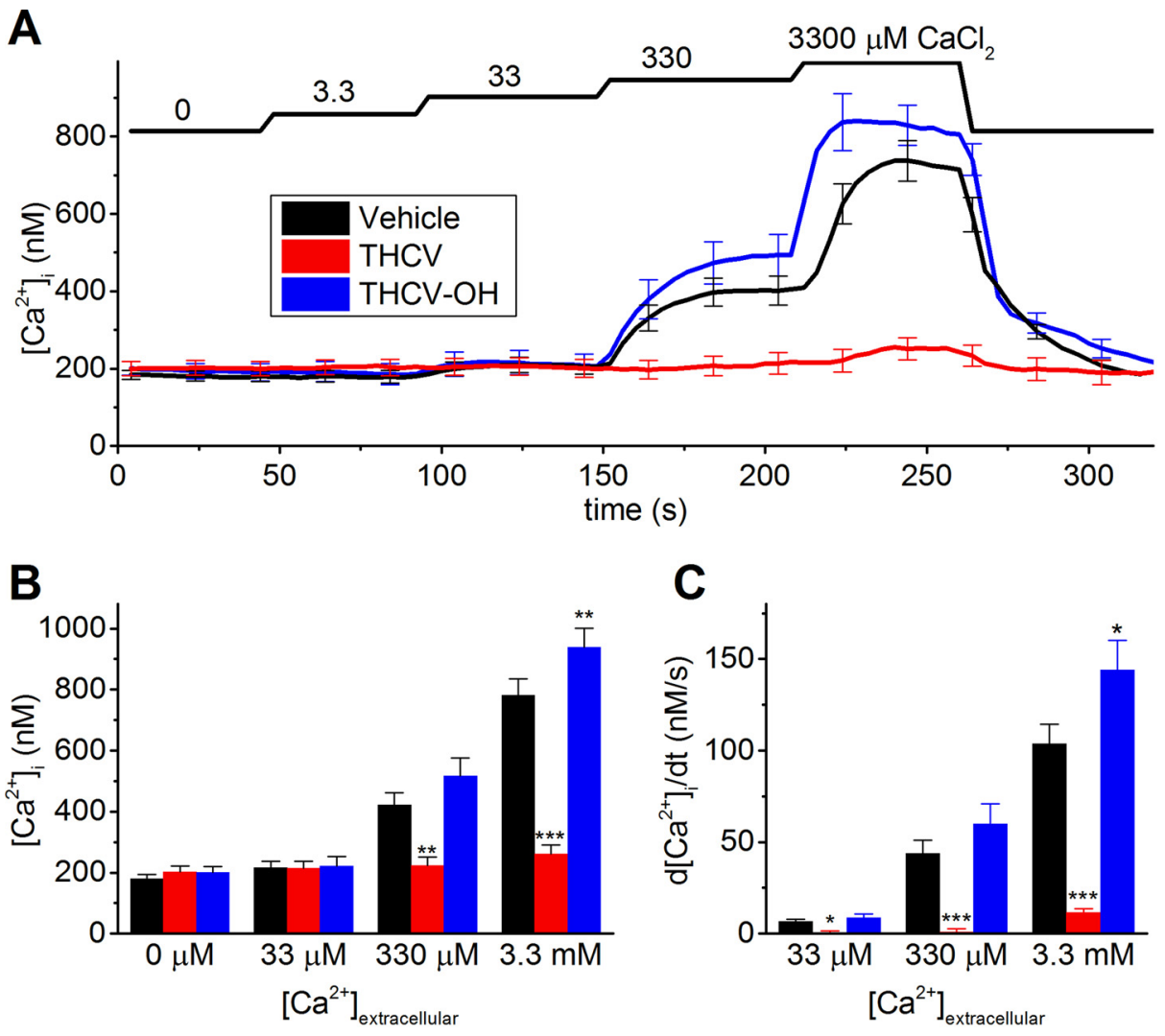

D

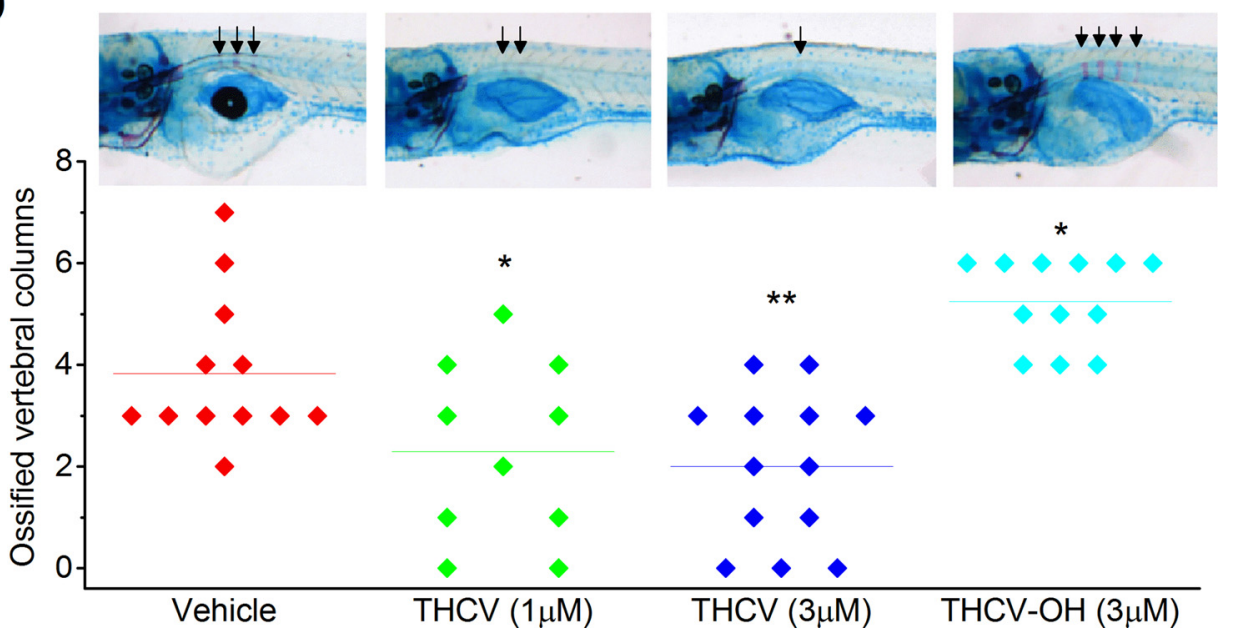

Fig. 3. Modulation of drTRPV5/6-dependent $\mathrm{Ca}^{2+}$-uptake and ossification by THCV and THCV-OH. (A) Representative intracellular $\mathrm{Ca}^{2+}$ measurement in HEK293 cells expressing drTRPV5/6 upon exposure to increasing concentrations of extracellular $\mathrm{Ca}^{2+}$, in control conditions and in the presence of THCV or $\mathrm{THCV}-\mathrm{OH}$ (both at $10 \mu \mathrm{M}$ ). Shown are the time-dependent changes in mean calcium concentration \pm SEM of single experiments in which 20 individual cells were assayed. (B, C) Peak intracellular $\mathrm{Ca}^{2+}$ concentrations (B) and peak rates of $\mathrm{Ca}^{2+}$ rise (C) obtained from experiments as in panel (A). *, ** and ***: $\mathrm{P}<0.05, \mathrm{P}<0.01$ and $\mathrm{P}<0.001$; two-way ANOVA with Tukey's post-hoc test. (D) Photographs of Alzarin-stained embryos (top; arrows indicate single ossified centra), and quantification of the number of ossified vertebral centra for individual embryos grown in medium supplemented with vehicle, THCV or $\mathrm{THCV}-\mathrm{OH}$ at the indicated concentrations. Horizontal lines indicate mean. * and **: $\mathrm{P}<0.05$ and $\mathrm{P}<0.01$ versus vehicle control; one-way ANOVA with Tukey's post hoc test. other malignancies, and it has been suggested that inhibition of TRPV6 may be the target of novel anticancer treatments [27]. Genetic ablation of either channel in mice leads to specific deficits in epithelial calcium handling. For instance, TRPV5 is highly expressed in $\mathrm{Ca}^{2+}$-reabsorbing epithelia in the kidney, and, concomitantly, TRPV5-deficient mice exhibit renal calcium wasting, as well as mild disturbances in bone structures. TRPV6-deficient mice exhibit male infertility attributed to an insufficient calcium transport by epididymial epithelium, as well as reduced intestinal $\mathrm{Ca}^{2+}$ absorption when placed on a low- $\mathrm{Ca}^{2+}$ diet, and impaired maternal-fetal calcium transport. Overall, however, under normal breeding conditions both the TRPV5- and the TRPV6-deficient mice develop with no obvious anatomical abnormalities, indicative of the existence of partial functional redundancy and/or compensatory mechanisms regulating global $\mathrm{Ca}^{2+}$ homeostasis. It is likely that combined elimination of TRPV5 and TRPV6 will lead to a much more severe disruption of $\mathrm{Ca}^{2+}$ homeostasis in mammals, but technical difficulties in creating combined TRPV5/TRPV6 double knockout mice have precluded a direct test of this hypothesis [27]. In contrast, genetic ablation in zebrafish of the single orthologue, drTRPV5/6, leads the lethal matt-und-schlapp phenotype [18]. This mutant is characterized by a severe reduction in organismal $\mathrm{Ca}^{2+}$ content and a full lack of ossification of the axial skeleton, which can be partially rescued by increasing the calcium content of the growth medium [18]. These findings indicated that drTRPV5/6 is essential for $\mathrm{Ca}^{2+}$ uptake, a process that mainly takes place in the gills and that is vital for zebrafish calcium homeostasis.

There is a growing interest in the use of phytocannabinoids for medical use. For instance, preclinical studies have provided evidence 
that THCV has beneficial effects on glycemic control in models of type 2 diabetes, reduces pentylenetetrazole-induced seizures, and causes pain relief in inflammatory models [28-30]. These effects have generally been attributed to modulation of $\mathrm{CB} 1$ and/or CB2 receptors: in vitro displacement assays indicate that THCV binds to both $\mathrm{CB}$ receptors with affinities in two digits nanomolar range, and behaves as a neutral CB1 antagonist and, depending on the in vitro and in vivo assays used, a CB2 agonist or antagonist [5]. Our present results suggest that THCV, in addition to its effects on CB1/CB2, may also influence the various physiological processes in humans involving TRPV5/TRPV6-dependent $\mathrm{Ca}^{2+}$ transport. Using zebrafish embryos as a vertebrate in vivo model, we found that including $1-3 \mu \mathrm{M}$ THCV in the medium caused a significant reduction in axial ossification, in line with its inhibitory effect on drTRPV5/6 currents and cellular calcium uptake, mimicking the matt-und-schlapp phenotype. In further support of the concept that drTRPV5/6 mediates the effect of THCV in zebrafish ossification, we observed that THCV - OH, a major metabolite of THCV in mammals, caused a significant potentiation of drTRPV5/6-mediated cellular $\mathrm{Ca}^{2+}$ uptake and enhanced ossification in the zebrafish embryo. Nevertheless, at this point we cannot fully exclude that the effects of THCV or THCV - OH on zebrafish ossification are dependent on other potential targets of THCV, such as the zebrafish orthologues of CB1 and CB2 [31,32].

Plasma concentrations of THCV in recreational cannabis users are typically in the low nanomolar range [33,34], which, based on our present results, would be too low to cause any significant effect on TRPV5 or TRPV6 activity. Likewise, the doses of THCV that have been used to ameliorate glycemic parameters or reduce inflammatory pain in vivo are unlikely to result in supra-micromolar THCV plasma concentrations $[28,30,35]$. Nevertheless, micromolar concentrations have been detected in plasma and brain of mice and rats treated i.p or p.o with $30 \mathrm{mg} / \mathrm{kg}$ of THCV [36], and the full pharmacokinetics of THCV upon repeated dosing are not known. Likewise, there is no quantitative information available on the levels of THCV - OH that occur in humans following THCV administration. Therefore, future work in mammalian models may be warranted to further explore potential effects of the use of THCV-based medicinal products on epithelial calcium transport and other TRPV5- or TRPV6-related processes in humans.

\section{Conflict of interest}

None.

\section{Author contributions}

$\mathrm{AJ}$ and TV performed and analysed patch-clamp and calcium imaging experiments, CS and AM performed and analysed zebrafish experiments, JVO provided essential experimental tools, TV and VDM designed experiments, TV coordinated the project and wrote the manuscript. All authors commented on the manuscript.

\section{Acknowledgements}

We thank all members of the Laboratory of Ion Channel Research for comments and discussion. This work was supported by grants from KU Leuven Research Council (PF-TRPLe and C1-TRPLe to T.V.).

\section{References}

[1] A. Ligresti, L. De Petrocellis, V. Di Marzo, From phytocannabinoids to cannabinoid receptors and endocannabinoids: pleiotropic physiological and pathological roles through complex pharmacology, Physiol. Rev. 96 (4) (2016) 1593-1659.

[2] L.A. Matsuda, S.J. Lolait, M.J. Brownstein, A.C. Young, T.I. Bonner, Structure of a cannabinoid receptor and functional expression of the cloned cDNA, Nature 346 (6284) (1990) 561-564.

[3] S. Munro, K.L. Thomas, M. Abu-Shaar, Molecular characterization of a peripheral receptor for cannabinoids, Nature 365 (6441) (1993) 61-65.
[4] A.A. Izzo, F. Borrelli, R. Capasso, V. Di Marzo, R. Mechoulam, Non-psychotropic plant cannabinoids: new therapeutic opportunities from an ancient herb, Trends Pharmacol. Sci. 30 (10) (2009) 515-527.

[5] R.G. Pertwee, A.C. Howlett, M.E. Abood, S.P. Alexander, V. Di Marzo, M.R. Elphick, P.J. Greasley, H.S. Hansen, G. Kunos, K. Mackie, R. Mechoulam, R.A. Ross, International union of basic and clinical pharmacology. LXXIX. Cannabinoid receptors and their ligands: beyond CB(1) and CB(2), Pharmacol. Rev. 62 (4) (2010) 588-631.

[6] M. Gees, G. Owsianik, B. Nilius, T. Voets, TRP channels, Compr. Physiol. 2 (1) (2012) 563-608.

[7] L. De Petrocellis, P. Orlando, A.S. Moriello, G. Aviello, C. Stott, A.A. Izzo, V. Di Marzo, Cannabinoid actions at TRPV channels: effects on TRPV3 and TRPV4 and their potential relevance to gastrointestinal inflammation, Acta Physiol. (Oxf) 204 (2) (2012) 255-266.

[8] L. De Petrocellis, A. Ligresti, A.S. Moriello, M. Allara, T. Bisogno, S. Petrosino, C.G. Stott, V. Di Marzo, Effects of cannabinoids and cannabinoid-enriched Cannabis extracts on TRP channels and endocannabinoid metabolic enzymes, Br. J. Pharmacol. 163 (7) (2011) 1479-1494.

[9] S.P. Alexander, J. Striessnig, E. Kelly, N.V. Marrion, J.A. Peters, E. Faccenda, S.D. Harding, A.J. Pawson, J.L. Sharman, C. Southan, J.A. Davies, The concise guide to pharmacology 2017/18: voltage-gated ion channels, Br. J. Pharmacol. 174 (Suppl 1) (2017) S160-S194.

[10] J. Vriens, B. Nilius, T. Voets, Peripheral thermosensation in mammals, Nat. Rev. Neurosci. 15 (9) (2014) 573-589.

[11] I. Vandewauw, K. De Clercq, M. Mulier, K. Held, S. Pinto, N. Van Ranst, A. Segal, T. Voet, R. Vennekens, K. Zimmermann, J. Vriens, T. Voets, A TRP channel trio mediates acute noxious heat sensing, Nature 555 (7698) (2018) 662-666.

[12] P.M. Zygmunt, J. Petersson, D.A. Andersson, H. Chuang, M. Sorgard, V. Di Marzo, D. Julius, E.D. Hogestatt, Vanilloid receptors on sensory nerves mediate the vasodilator action of anandamide, Nature 400 (6743) (1999) 452-457.

[13] H. Watanabe, J. Vriens, J. Prenen, G. Droogmans, T. Voets, B. Nilius, Anandamide and arachidonic acid use epoxyeicosatrienoic acids to activate TRPV4 channels, Nature 424 (6947) (2003) 434-438.

[14] A. Olah, B.I. Toth, I. Borbiro, K. Sugawara, A.G. Szollosi, G. Czifra, B. Pal, L. Ambrus, J. Kloepper, E. Camera, M. Ludovici, M. Picardo, T. Voets, C.C. Zouboulis, R. Paus, T. Biro, Cannabidiol exerts sebostatic and antiinflammatory effects on human sebocytes, J. Clin. Invest. 124 (9) (2014) 3713-3724.

[15] M.J. Caterina, TRP channel cannabinoid receptors in skin sensation, homeostasis, and inflammation, ACS Chem. Neurosci. 5 (11) (2014) 1107-1116.

[16] J.G. Hoenderop, R. Vennekens, D. Muller, J. Prenen, G. Droogmans, R.J. Bindels, B. Nilius, Function and expression of the epithelial $\mathrm{Ca}(2+)$ channel family: comparison of mammalian ECaC1 and 2, J. Physiol. 537 (Pt 3) (2001) 747-761.

[17] R. Vennekens, J.G. Hoenderop, J. Prenen, M. Stuiver, P.H. Willems, G. Droogmans, B. Nilius, R.J. Bindels, Permeation and gating properties of the novel epithelial Ca (2+) channel, J. Biol. Chem. 275 (6) (2000) 3963-3969.

[18] J. Vanoevelen, A. Janssens, L.F. Huitema, C.L. Hammond, J.R. Metz, G. Flik, T. Voets, S. Schulte-Merker, Trpv5/6 is vital for epithelial calcium uptake and bone formation, FASEB J. 25 (9) (2011) 3197-3207.

[19] J.G. Hoenderop, B. Nilius, R.J. Bindels, Calcium absorption across epithelia, Physiol. Rev. 85 (1) (2005) 373-422.

[20] M. Westerfield, The zebrafish book, A Guide for the Laboratory Use of Zebrafish (Danio Rerio), 5th edition, University of Oregon Press, 2007.

[21] C.B. Kimmel, W.W. Ballard, S.R. Kimmel, B. Ullmann, T.F. Schilling, Stages of embryonic development of the zebrafish, Dev. Dyn. 203 (3) (1995) 253-310.

[22] M.B. Walker, C.B. Kimmel, A two-color acid-free cartilage and bone stain for zebrafish larvae, Biotech. Histochem. 82 (1) (2007) 23-28.

[23] T. Voets, A. Janssens, J. Prenen, G. Droogmans, B. Nilius, Mg2+-dependent gating and strong inward rectification of the cation channel TRPV6, J. Gen. Physiol. 121 (3) (2003) 245-260.

[24] T. Voets, J. Prenen, A. Fleig, R. Vennekens, H. Watanabe, J.G. Hoenderop, R.J. Bindels, G. Droogmans, R. Penner, B. Nilius, CaT1 and the calcium releaseactivated calcium channel manifest distinct pore properties, J. Biol. Chem. 276 (51) (2001) 47767-47770.

[25] M.A. ElSohly, S. Feng, T.P. Murphy, A.W. Warrington, S. Ross, A. Nimrod, Z. Mehmedic, N. Fortner, Identification and quantitation of 11-nor-delta9-tetrahydrocannabivarin-9-carboxylic acid, a major metabolite of delta9-tetrahydrocannabivarin, J. Anal. Toxicol. 25 (6) (2001) 476-480.

[26] C.J. Lucas, P. Galettis, J. Schneider, The pharmacokinetics and the pharmacodynamics of cannabinoids, Br. J. Clin. Pharmacol. (2018).

[27] C. Fecher-Trost, U. Wissenbach, P. Weissgerber, TRPV6: from identification to function, Cell Calcium 67 (2017) 116-122.

[28] D. Bolognini, B. Costa, S. Maione, F. Comelli, P. Marini, V. Di Marzo, D. Parolaro, R.A. Ross, L.A. Gauson, M.G. Cascio, R.G. Pertwee, The plant cannabinoid Delta9tetrahydrocannabivarin can decrease signs of inflammation and inflammatory pain in mice, Br. J. Pharmacol. 160 (3) (2010) 677-687.

[29] A.J. Hill, S.E. Weston, N.A. Jones, I. Smith, S.A. Bevan, E.M. Williamson, G.J. Stephens, C.M. Williams, B.J. Whalley, Delta(9)-Tetrahydrocannabivarin suppresses in vitro epileptiform and in vivo seizure activity in adult rats, Epilepsia 51 (8) (2010) 1522-1532.

[30] E.T. Wargent, M.S. Zaibi, C. Silvestri, D.C. Hislop, C.J. Stocker, C.G. Stott, G.W. Guy, M. Duncan, V. Di Marzo, M.A. Cawthorne, The cannabinoid Delta(9)tetrahydrocannabivarin (THCV) ameliorates insulin sensitivity in two mouse models of obesity, Nutr. Diabetes 3 (2013) e68.

[31] I. Bab, A. Zimmer, Cannabinoid receptors and the regulation of bone mass, Br. J. Pharmacol. 153 (2) (2008) 182-188.

[32] M.T. Akhtar, S. Ali, H. Rashidi, F. van der Kooy, R. Verpoorte, M.K. Richardson, 
Developmental effects of cannabinoids on zebrafish larvae, Zebrafish 10 (3) (2013) 283-293.

[33] M.N. Newmeyer, M.J. Swortwood, A.J. Barnes, O.A. Abulseoud, K.B. Scheidweiler, M.A. Huestis, Free and glucuronide whole blood cannabinoids' pharmacokinetics after controlled smoked, vaporized, and oral Cannabis administration in frequent and occasional Cannabis users: identification of recent Cannabis intake, Clin. Chem. 62 (12) (2016) 1579-1592.

[34] M.J. Swortwood, M.N. Newmeyer, M. Andersson, O.A. Abulseoud, K.B. Scheidweiler, M.A. Huestis, Cannabinoid disposition in oral fluid after controlled smoked, vaporized, and oral cannabis administration, Drug Test. Anal. 9 (6) (2017) 905-915.
[35] K.A. Jadoon, S.H. Ratcliffe, D.A. Barrett, E.L. Thomas, C. Stott, J.D. Bell, S.E. O'Sullivan, G.D. Tan, Efficacy and safety of Cannabidiol and Tetrahydrocannabivarin on glycemic and lipid parameters in patients with type 2 diabetes: a randomized, double-blind, placebo-controlled, parallel group pilot study, Diabetes Care 39 (10) (2016) 1777-1786.

[36] S. Deiana, A. Watanabe, Y. Yamasaki, N. Amada, M. Arthur, S. Fleming, H. Woodcock, P. Dorward, B. Pigliacampo, S. Close, B. Platt, G. Riedel, Plasma and brain pharmacokinetic profile of cannabidiol (CBD), cannabidivarine (CBDV), Delta (9)-tetrahydrocannabivarin (THCV) and cannabigerol (CBG) in rats and mice following oral and intraperitoneal administration and CBD action on obsessive-compulsive behaviour, Psychopharmacology 219 (3) (2012) 859-873. 